\title{
A unique "turn-on" fluorescence signalling strategy for highly specific detection of ascorbic acid using carbon dots as sensing probe
}

\author{
Jessica Fung Yee Fong a,b, Suk Fun Chin ${ }^{\mathrm{c}}$, Sing Muk $\mathrm{Ng}^{\mathrm{a}, \mathrm{b}, *}$ \\ a Swinburne Sarawak Research Centre of Sustainable Technologies, Swinburne University of Technology Sarawak Campus, Jalan Simpang Tiga, 93350 \\ Kuching, Sarawak, Malaysia \\ ${ }^{\mathrm{b}}$ Faculty of Engineering, Computing and Science, Swinburne University of Technology Sarawak Campus, Jalan Simpang Tiga, 93350 Kuching, Sarawak, \\ Malaysia \\ ${ }^{\mathrm{c}}$ Faculty of Resource Science and Technology, Universiti Malaysia Sarawak, 94300 Kota Samarahan, Sarawak, Malaysia
}

\section{A R T I C L E I N F O}

\section{Article history:}

Received 4 March 2016

Received in revised form

27 May 2016

Accepted 30 May 2016

Available online 31 May 2016

Keywords:

Ascorbic acid

Fluorescence "turn-on"

Carbon dots

Sustainable sensing

Optical sensing

\begin{abstract}
A B S T R A C T
Carbon dots (CDs) that showed strong blue fluorescence were successfully synthesised from sodium alginate via furnace pyrolysis. The single step pyrolytic synthesis was simple to perform while yielded CDs with high photostability, good water solubility and minimum by-products. In order to design the probe with "turn-on" sensing capability, the CDs were screened against a series of metal cations to first "turn-off" the fluorescence. It was found that ferric ions $\left(\mathrm{Fe}^{3+}\right)$ were most responsive and effective in quenching the fluorescence of CDs. Based on this observation, the conditioning of the probe was performed to ensure the fluorescence was completely quenched, while not overloading the system with $\mathrm{Fe}^{3+}$. At the optimised condition, the CDs- $\mathrm{Fe}^{3+}$ mixture served as a highly specific detection probe for ascorbic acid (AA). The analytical potential of the probe was evaluated and showed a good linear range of response for AA concentration of $24-40 \mu \mathrm{g} / \mathrm{mL}$. The selectivity study against other possible co-existing species was carried out and proved that our unique "turn-on" fluorescence signalling strategy was highly effective and selective towards AA as the target analyte. The probe was demonstrated for quantification of AA in real samples, which was the commercially available vitamin $C$ supplement. The result showed good accuracy with minimum deviation from standard method adopted for validation purpose.
\end{abstract}

(c) 2016 Elsevier B.V. All rights reserved.

\section{Introduction}

Ascorbic acid (AA) or more well-known as vitamin $C$ by the community is a strong antioxidant that can reduce oxidative stress in body and therefore believed to be able to lower cancer and cardiovascular risks (Alpsoy and Yalvac, 2011; Bendich et al., 1986). In addition, AA is essentially taken in our daily diet to fulfil the body requirement for the development and maintenance of scar tissue, blood vessels and cartilage. Besides, AA is involved directly in creating a series of other small biomolecules such as adenosine triphosphate (ATP), dopamine, peptide hormones, etc. (Naidu, 2003). The deficiency of AA in the body will lead to a medical condition termed as scurvy (Magiorkinis et al., 2011). Scurvy patients are incapable of generating collagen that is vital for new tissue replacement (Agarwal et al., 2015). An excessive amount of AA may not be harmful to us but an overdose of AA from supplements may result in conditions such as diarrhoea, nausea,

\footnotetext{
* Corresponding author at: Swinburne Sarawak Research Centre of Sustainable Technologies, Swinburne University of Technology Sarawak Campus, Jalan Simpang Tiga, 93350 Kuching, Sarawak, Malaysia.

E-mail address: smng@swinburne.edu.my (S.M. Ng).
}

heartburn, kidney stones, etc. As recommended by Food and Nutrition Board under the Institute of Medicine of the National Academies, the adequate daily intake of vitamin $C$ for a male adult is $90 \mathrm{mg}$ by average and $75 \mathrm{mg}$ for a female adult. The tolerable limit for daily intake is estimated at $2000 \mathrm{mg}$ per day for male and female adults (I.o.M.F.a.N. and Board, 2001). Considering the important roles of AA in our daily life, it will be beneficial to monitor and determine its content in food and pharmaceutical products to ensure adequate intake. Besides, AA detection in blood serum is also an important diagnosis of scurvy.

There are plenty of methods dedicated for the detection of AA. Despite this, there are still continuous efforts in the search for better and more specific detection of AA for diagnosis purposes and daily uses for the public. AA is readily available in our daily life, whether in fresh vegetables and fruits or in the form of pharmaceutical products such as vitamin $C$ or multivitamin tablets. It would be handy to have a portable sensor for AA to be used in our daily life. Otherwise, the existing methods are mainly carried out in the laboratory, such as colorimetric methods, titrimetry, voltammetry, potentiometry, chromatography, flow injection analyses, and etc. which are not very accessible to the public for fast and efficient detection of AA (Arya et al., 2000). 